\title{
Será que a aula acabou? Um estudo sobre as práticas de escrita de estudantes do Ensino Médio no Whatsapp
}

\author{
Maria Jacy Maia Velloso \\ Departamento de Métodos e Técnicas Educacionais - Universidade Estadual de Montes \\ Claros (UNIMONTES) - Montes Claros - MG - Brasil \\ m.jacy@hotmail.com
}

\begin{abstract}
The present research examined the writing practices of high school students to understand how young people appropriate these practices in the use of the WhatsApp application and employ them in the production of school knowledge. It is a qualitative research, and since it is a work that has the objective of investigating and documenting a concrete situation of writing practices in the use of the WhatsApp application, the methodology used was the research of ethnographic approach. It was verified that the class did not end with leaving school, and that being connected to the cell phone, allowed the expansion of the process of teaching and learning beyond the classroom.
\end{abstract}

Resumo. A presente pesquisa analisou as práticas de escrita de estudantes do ensino médio para entender como os jovens se apropriam dessas práticas no uso do aplicativo WhatsApp e as empregam na produção de conhecimento escolar. Trata-se de uma pesquisa com abordagem qualitativa e, por ser um trabalho que tem o objetivo de investigar e documentar uma situação concreta de práticas de escrita no uso do aplicativo WhatsApp, a metodologia utilizada foi a pesquisa de abordagem etnográfica. Constatamos que a aula não terminou com a saída da escola, e que estar conectado ao celular, permitiu a ampliação do processo de ensino e aprendizagem para além da sala de aula.

\section{Introdução}

O avanço tecnológico possibilitou aos pensadores a análise sobre a introdução da cultura digital no contexto educacional. Hoje, entre as preocupações que mobilizam alguns dos educadores, está a que se relaciona à contemporaneidade de um mundo repleto de Tecnologias Digitais de Informação e Comunicação (TDIC) e à diversidade de novos saberes que se exige do cidadão. Um dos grandes desafios da escola é proporcionar o exercício dos direitos e deveres plenos, uma vez que o processo de escolarização, dentre outros conhecimentos, permite ao leitor desenvolver uma leitura ampla do mundo, que vai além do entendimento das palavras, na medida em que desenvolve o domínio da linguagem.

As mídias digitais passaram a ser incorporadas na vida dos adolescentes, que representam um terço da população mundial e um terço de usuários da internet no mundo. Segundo a UNESCO (2015), os dispositivos móveis, tais como os celulares, estão entre as tecnologias digitais mais difundidas da história. Entre a população mundial, atualmente de 7 bilhões de pessoas, mais de 6 bilhões têm acesso a um 
VII Congresso Brasileiro de Informática na Educação (CBIE 2018)

Anais dos Workshops do VII Congresso Brasileiro de Informática na Educação (WCBIE 2018)

telefone celular. Embora sejam utilizados principalmente para comunicação, eles representam, cada vez mais, uma porta de entrada para textos de diversos formatos, de pequena ou de grande extensão (UNESCO, 2015).

No Brasil, os dados da TDIC Domicílios 2016 revelam que os dispositivos utilizados pelos alunos do ensino médio para acessar a Internet são: telefone celular (92\%); computador de mesa (45\%); computador portátil ou notebook (42\%); e tablet $(19 \%)$ (COMITÊ GESTOR DA INTERNET NO BRASIL, 2016). À medida que cresce o acesso à internet, os alunos têm acesso a recursos por meio de diversas ferramentas de comunicação, como sites de redes sociais e aplicativos para smartphones (FOGG, 2010). O WhatsApp tem se mostrado como um dos aplicativos com mais adesão entre os usuários de dispositivos móveis, sendo um dos mais populares e estando disponível para Android, iPhone, Windows Phone, BlackBerry e Nokia (ALSALEEM, 2013).

Como observa Alsaleem (2013), o WhatsApp não cobra por texto enviado, pois envia mensagens por meio de uma conexão de dados da Internet. Assim, torna-se uma ferramenta sem custos adicionais para mensagens instantâneas, representando uma forma de socializar sem depender de pais ou responsáveis, além de suportar mensagens multimodais com textos simples, imagens, arquivos de áudio e vídeos.

Neste sentido, a tecnologia, especificamente o celular, se faz presente nos processos escolares, não pelo uso dos professores no processo de ensino e aprendizagem que ainda se mostra incipiente, mas por estarem incorporadas ao modo de ser, representam escolhas sociais e culturais dos jovens na atualidade, ou seja, as culturas estão presentes na escola e vamos produzindo novas culturas a partir do convívio com as novas tecnologias e de seus usuários ( MONTEIRO, 2006).

Assim, o objetivo desta pesquisa foi identificar as práticas de letramento de estudantes através do celular, isto é, quais são as práticas de escrita identificadas nos dispositivos móveis e como essas práticas provocadas pelas TDIC, especialmente pelas tecnologias móveis, afetam a produção de conhecimento escolar pelos estudantes do ensino médio.

\section{Letramento: práticas de escrita no contexto social}

O letramento é um campo de pesquisa que vem contribuindo para a reflexão sobre as possibilidades de usos sociais da leitura e escrita em contextos sociais diferenciados, incluindo contextos digitais, e sobre como usos locais da escrita estão relacionados à movimentos globais. Scribner e Cole (apud Kleiman, 1995, p. 19) definem letramento "como um conjunto de práticas sociais que usam a escrita como sistema simbólico e como tecnologia em contextos específicos para objetivos específicos". No contexto da concepção de letramento situado, propomos nesta pesquisa, o estudo das práticas de letramento dos alunos, tomando como referência as práticas de escrita que conferem habilidades para que esses alunos possam utilizar o celular para interagir, produzir conteúdos e buscar informações, ou seja, para a construção de habilidades de interação com a mídia a partir de uma perspectiva que contemple tanto o aspecto social quanto o cognitivo, compreendendo essa prática como sendo uma nova forma de letramento. 
VII Congresso Brasileiro de Informática na Educação (CBIE 2018)

Anais dos Workshops do VII Congresso Brasileiro de Informática na Educação (WCBIE 2018)

Analisando as situações em que a língua escrita é parte integrante da natureza da interação entre os participantes e de seus processos de interpretação, podemos afirmar que as pessoas interagem oralmente com a mediação da leitura ou da escrita. Existe ainda a interação a distância - autor-leitor ou leitor-autor. Nesse sentido, todo uso da língua, em diferentes modos (textos, imagens, áudios), é funcional, na medida em que proporciona a participação das pessoas em situações específicas, qualquer que seja sua finalidade em suas práticas sociais.

Alguns teóricos do campo do letramento como prática social, principalmente Street (1984, 2003, 2010, 2014) e Kalman (2004, 2009, 2013), auxiliaram na compreensão de práticas de leitura e de escrita a partir dos estudos de textos produzidos no cotidiano das pessoas e da tentativa de documentar letramentos emergentes em diferentes contextos locais. Desse modo, tendo em vista o objeto de estudo desta pesquisa, a perspectiva de letramento a ser adotada terá como fundamento os Novos Estudos sobre Letramento ou New Literacy Studies (NLS), uma vertente que se desenvolveu a partir dos trabalhos de Heath (1983) e de Street (1984), que entendem o letramento como prática social.

Os NLS apresentam dois modelos de letramento: o modelo "autônomo" e o "ideológico" (Street, 1984, p.18), e abordam ainda a estruturação dos conceitos de "evento de letramento" e "prática de letramento" (HEATH, 1983; STREET, 1988). O modelo autônomo de letramento diz respeito à crença de que o letramento tem um sentido singular, assumindo que há um letramento único para todos, em todos os lugares. Nesse modelo de letramento, a escrita é considerada autônoma, não se relacionando ao contexto no qual está inserida, tendo assim "efeitos previsíveis sobre o desenvolvimento cognitivo ou sociocultural de indivíduos e de grupos" (BUZATO, 2007, p.113). Nessa perspectiva, o letramento é dissociado do contexto sociocultural em que ocorre, sendo considerado um fenômeno isolado, independente dos aspectos econômicos, políticos e das relações de poder nas quais possa estar inserido.

Assim, em contraposição ao modelo autônomo, o modelo ideológico reconhece a natureza social do letramento, privilegiando a análise de aspectos culturais, políticos, econômicos e relações de poder. Conforme argumenta Street, "as formas como as pessoas se apropriam da leitura e da escrita estão endereçadas e enraizadas nas concepções de conhecimento, identidade e ser" (STREET, 2003, p. 78).

Dessa forma, no contexto digital, o letramento está relacionado às práticas sociais e à inúmeras maneiras de se engajar na construção de significado, mediada por textos que são produzidos, recebidos, distribuídos, trocados via codificação digital (LANKSHEAR; KNOBEL, 2006). Considera-se, assim, que "a tecnologia não determina a prática. É sempre o contrário: as práticas sociais determinam como usamos a tecnologia" (STREET, 2010, p. 45).

Assim, buscamos compreender a pluralidade de práticas culturais de escrita, cuja compreensão só é possível ao se considerar o contexto particular em que se desenvolvem. 
VII Congresso Brasileiro de Informática na Educação (CBIE 2018)

Anais dos Workshops do VII Congresso Brasileiro de Informática na Educação (WCBIE 2018)

\section{Metodologia}

Decidimos por uma abordagem qualitativa (GOLDENBERG, 1999) e, por ser um trabalho que tem o objetivo de investigar e documentar uma situação concreta de práticas de escrita no uso do celular, a metodologia que consideramos mais adequada foi a pesquisa de abordagem etnográfica.

A perspectiva etnográfica representa uma "revolução conceitual" (SOARES, 2010, p.56) por buscar compreender as diferentes culturas nas quais estão presentes a escrita e seu significado social. Essa perspectiva centra-se no letramento como prática social em contextos mais amplos, oferecendo uma posição metodológica e ideológica para debater a aparente neutralidade das práticas de escrita, oferecendo ainda conceitos para a análise da diversidade social e cultural dos diferentes grupos sociais (KALMAN e STREET, 2009).

O interesse na aplicação da etnografia em uma variedade de campos e configurações reconhece o uso das mídias digitais como parte integrante da vida cotidiana. Portanto, ao analisar a construção de significados, uma estratégia importante é conhecer como as maneiras de expressar e as formas de escrita no ambiente digital são construídas pelos participantes em diferentes contextos. Os estudos das TDICs nas abordagens etnográficas apresentam-se como processos socioculturais de significação, com vistas ao conhecimento de manifestações particulares de ação semiótica no ambiente digital.

Para a coleta de dados, participamos de um grupo de WhatsApp denominado "30 rão", composto por alunos do terceiro ano do Ensino Médio de uma escola pública na cidade de Montes Claros, com idades entre 16 e 18 anos. Os dados aqui apresentados foram coletados no momento em que o curso estava em andamento, participamos de um grupo de WhatsApp denominado " $3^{\circ}$ rão", composto por alunos do terceiro ano do Ensino Médio de uma escola pública na cidade de Montes Claros, com idades entre 16 e 18 anos. Foram analisadas mais de 650 mensagens enviadas por 19 estudantes, em relação a um total de 24 estudantes matriculados e frequentes na sala de aula. O processo de análise se deu através da construção de categorias, a partir da sistematização das mensagens enviadas pelos participantes.

\section{Resultados e discussões}

Com base nas observações das mensagens enviadas pelos estudantes do grupo analisado evidenciamos algumas características relacionadas às suas práticas de escrita. A escrita no WhatsApp caracterizou-se por ser breve e concisa, utilizando muitos recursos de abreviação. Os alunos lançavam mão de recursos visuais para expressarem sentimentos e expressões, e para se comunicarem. Dessa forma, os diferentes modos de escrita representaram diferentes possibilidades e potencialidades para criar significado. As apropriações que ocorreram por meio da escrita no contexto digital foram construídas como forma de conhecer e de participar do espaço de sociabilidade e de entretenimento proporcionado pelo contexto digital, estando diretamente relacionadas aos interesses dos jovens. Os alunos utilizavam os posts como instrumento de conversa e ainda como instrumento de aprendizagem. 
VII Congresso Brasileiro de Informática na Educação (CBIE 2018)

Anais dos Workshops do VII Congresso Brasileiro de Informática na Educação (WCBIE 2018)

As práticas de escrita na rede social estavam associadas aos propósitos de comunicação de cada aluno, e foram utilizadas para paquerar, para combinar encontros, para avisar sobre um imprevisto, para curtir uma postagem e para responder a mensagens, sendo mais visíveis para os interesses de questões relacionadas ao cotidiano. Segundo Street (2003, p.6) "as maneiras pelas quais as pessoas lidam com leitura e escrita estão enraizadas em concepções de conhecimento, identidade e ser". Esse autor enfatiza que os letramentos estão sempre inseridos nas práticas sociais (como o mercado de trabalho ou outros contextos) e, portanto, os efeitos de aprendizagem de determinados letramentos dependem da participação em contextos particulares. Dessa forma, nas interações entre os participantes em conversas direcionadas a outros usuários foram frequentes as marcações de textos escritos contendo@s, como: @laura@pedro @LuizaM.

A análise dos eventos de letramento ressalta as formas e os conteúdos da escrita realizada pelos alunos. A escrita durante o período observado esteve presente na maioria das mensagens enviadas, ou seja, foram poucos os momentos em que não se observou o uso da língua escrita. Alguns alunos se comunicavam por áudio e outros enviavam emoticons como forma de significação. As gravações de áudio que os participantes postaram para realizar as tarefas acabaram por se tornar ferramentas para $o$ desenvolvimento habilidades relacionadas aos conteúdos estudados, oportunizando também a troca de saberes entre os jovens, uma vez que o aplicativo permite a criação de grupos para a troca de mensagens entre os usuários envolvidos.

Imagem, escrita, imagem em movimento são exemplos de formas utilizadas na constituição de textos no ambiente digital. Para dar significado ao que era escrito, muitas vezes a escrita estava acompanhada de imagens. $\mathrm{O}$ uso da imagem e da escrita como modo de construção de significado (JEWITT, 2008) levou-nos a sugerir que as representações multimodais nas postagens referem-se a uma forma que combina textos escritos e imagens para a produção de sentidos. O uso de outros modos de representação, como imagens ou vídeos nas postagens, oportunizou a expressão do significado através deles, tanto isoladamente quanto em combinações. A análise das postagens nos permitiu identificar que as imagens combinadas à escrita revelam uma visão da multimodalidade baseada nos pressupostos propostos por Jewitt (2009), uma vez que cada modo em um conjunto multimodal é entendido para a significação da ação comunicativa. Nos dados coletados, as decisões tomadas, no que diz respeito à inclusão de imagens combinadas à escrita, revelam as opções para transmitir significado sobre os aspectos relacionados tanto ao seu cotidiano quanto às atividades escolares.

Verificamos ainda que o espaço de sociabilidade também foi utilizado como espaço escolarizado para compartilhamento de tarefas escolares como atividades fotocopiadas e escritas, realizadas por professores no quadro negro. Os alunos também utilizaram esse espaço para ampliação das discussões em sala de aula como ocorreu com o debate promovido por uma professora sobre "Ideologia de gênero". Eles elogiaram o debate e comentaram sobre as ideias apresentadas pelos alunos, conforme os posts de uma aluna (Figura 1). 
VII Congresso Brasileiro de Informática na Educação (CBIE 2018)

Anais dos Workshops do VII Congresso Brasileiro de Informática na Educação (WCBIE 2018)

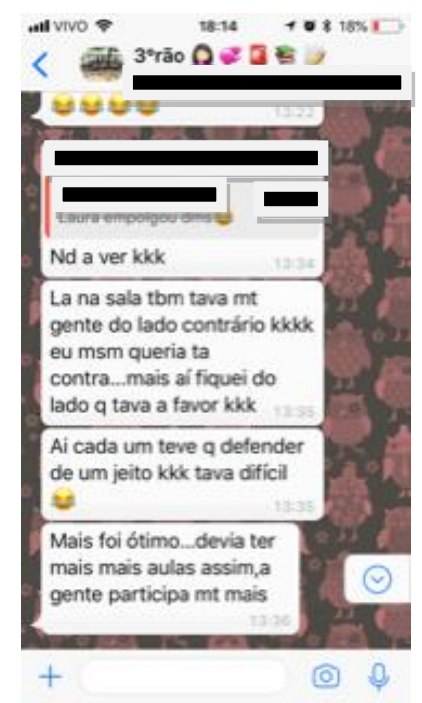

Figura 1 - Captura de tela do WhatsApp

Percebemos, pelo post, que a aluna teve mais liberdade de expor suas ideias sobre o assunto na rede social do que em sala de aula. Ela demonstrou que gostaria de expor seu pensamento, mas que, no contexto da sala de aula, não teve oportunidade ou vontade de expressar/defender seu ponto de vista. Em seguida manifestou sua opinião sobre os debates em sala de aula, elogiando a metodologia utilizada pela professora, o que foi aplaudido por outros colegas em outros comentários. Observamos, com isso, que os alunos parecem revelar mais sobre si na rede social que nas aulas presenciais.

Outras formas de uso da rede social foram a divulgação de matérias e pesquisas escritas no quadro negro (Figuras 2 e 3), comentários sobre a participação de alunos nas aulas, divulgação de data de provas e eventos, atividades escolares e horários, como podemos verificar nos posts a seguir:

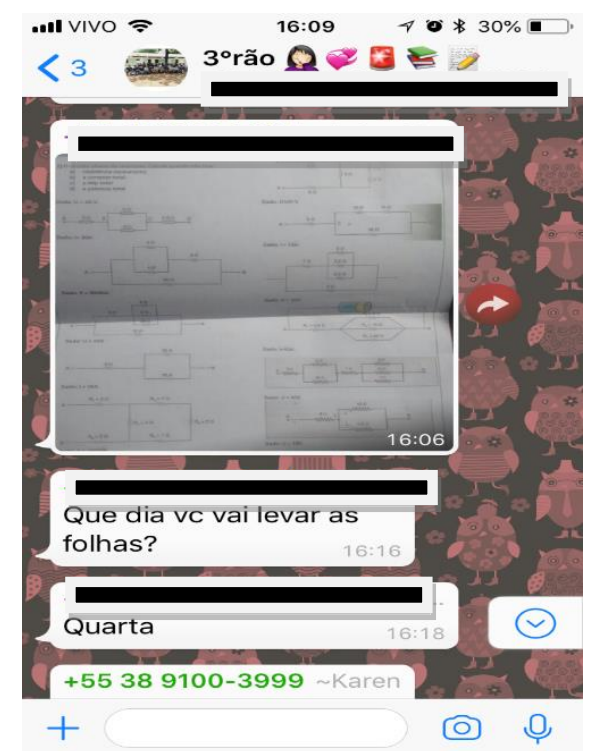

Figura 2 - Captura de tela do WhatsApp 
VII Congresso Brasileiro de Informática na Educação (CBIE 2018)

Anais dos Workshops do VII Congresso Brasileiro de Informática na Educação (WCBIE 2018)

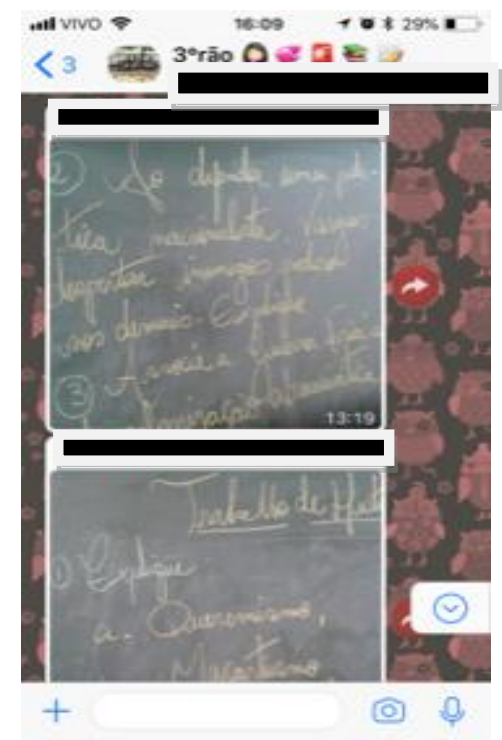

Figura 3. Captura de tela do WhatsApp

Os participantes criaram seu próprio ambiente, semelhante ao que eles poderiam encontrar em suas salas de aula. Ao seu modo, encontraram uma maneira conveniente de procurar ajuda, de responder às perguntas e de colaborar com as atividades escolares durante o horário pós-escolar. Nas situações de realização das tarefas escolares que, na maioria das vezes eram compartilhadas entre os alunos, predominava o intercâmbio de ideias e a construção da solidariedade, fazendo com que os alunos trocassem informações sobre os conteúdos dos textos, construindo seus conhecimentos em função de uma situação demandada pela escola.

\section{Conclusões}

As evidências mostradas ao longo desta pesquisa fornecem uma base empírica para discutir como as práticas de leitura e de escrita, através de dispositivos móveis, desempenham um papel na vida dos estudantes. A convergência dos múltiplos modos de representação (linguagem, escrita, imagens, gráficos, ícones) e a presença de ferramentas tecnológicas acrescentam uma nova dimensão à definição das práticas de escrita no contexto digital. As diferentes experiências de práticas de escrita revelam modos e estratégias variadas para compreender e escrever textos no contexto digital. Os alunos apropriaram-se da rede social WhatsApp em suas diversas práticas sociais, apesar de ser, neste caso em específico, um grupo formado por estudantes de uma turma do terceiro ano do ensino médio, cujo contexto poderia, prioritariamente, estar associado apenas às questões escolares. Em suas práticas sociais, os estudantes apropriaram-se da ferramenta pelas motivações que emergiram no seu cotidiano e, em função das demandas, utilizaram a rede social para as atividades escolares, com a divulgação de informações relevantes para eles.

Os resultados discutidos indicam que os significados das práticas de escrita no WhatsApp para a construção de sentido são informados pelos usos sociais. A análise das 
ações geradoras dessas práticas no celular evidenciou que as mensagens se mostraram consonantes com as atividades escolares, se mostrando também como uma forma de construção de sentidos e significados para determinadas situações sociais.

O aplicativo representou um artefato tecnológico bastante utilizado por seus usuários para compartilhamento de informações diversas. As práticas de escrita desses alunos estão vinculadas à sua participação nas redes sociais, sendo utilizadas para interações com os amigos e realização das tarefas escolares. Escrever, para esses alunos, põe em evidência diversos modos para a escrita de textos em ambiente digital. Conforme os usos e significados, a escrita adquire características verbais, visuais, sonoras e coloridas.

A partir do estudo dessas práticas de escrita, constatamos que a aula não termina com a saída da escola, estar conectado ao celular, para esses estudantes, permitiu a ampliação das discussões na sala de aula. Os resultados apontam para a potencialidade da ferramenta, a qual permite que os alunos mantenham contato e interajam de modo significativo contribuindo para o seu próprio aprendizado e para o aprendizado do outro. Assim, concluímos que há diferentes usos do celular fomentando outras formas de produzir conhecimentos pelos alunos que muitas vezes são ignoradas ou não reconhecidas pelas instituições escolares.

\section{Referências}

ALSALEEM, Basma Issa Ahmad. The effect of "whatsAap" electronic dialogue journaling on improving writing vocabulary word choice and voice of EFL Undergraduate Saudi Students. AWEJ, v. 04, n. 03. 2013. Disponível em: < http://goo.gl/HrD0gq $>$. Acesso em: 15 jun. 2018. ISSN 2229-9327.

BUZATO, M. E. K. Entre a fronteira e a periferia: linguagem e letramento na inclusão digital. 2007. 285 f. Tese (Doutorado em Linguística Aplicada) -Universidade Estadual de Campinas, Programa de Pós-graduação e Linguística Aplicada, Campinas, 2007.

DE OLIVEIRA, Maria Bernadete Fernandes; SZUNDY, Paula Tatiane Carréra. Práticas de multiletramentos na escola: por uma educação responsiva à contemporaneidade. Bakhtiniana. Revista de Estudos do Discurso, v. 9, n. 2, p. 184-205/Eng. 191-210, 2014.

FOGG, P. . The professor-what to do when home is just another word for the office.

Chronicle of Higher Education 54 (21), B12 - 2010.

GOLDEMBERG, M. A arte de pesquisar: como fazer pesquisa qualitativa em ciências sociais. Rio de Janeiro: Record, 1999.

HEATH, S. B. Ways With Words. Cambridge: CUP, 1983.

JEWITT, C. Multimodality and Literacy in School Classrooms. Review of Research in Education, 32 (1), p. 241-267, 2008. p. 241-267. 
VII Congresso Brasileiro de Informática na Educação (CBIE 2018)

Anais dos Workshops do VII Congresso Brasileiro de Informática na Educação (WCBIE 2018)

KALMAN, J.; STREET, B. (Orgs.). Lectura, Escritura y Matemáticas Como Práticas Sociales: diálogos com America Latina. México City: Siglo XXI Editores, 2009.

KALMAN, J. GPS Technology, Map Reading and everyday location practices in a fishing community. In: In: KALMAN, J.; STREET, B. R. (Eds.). Literacy and numeracy in Latin America: Local perspectives and beyond. New York, London: Routledge, 2013. p. 67-81.

KLEIMAN, A. (Org.). Os significados do letramento: uma nova perspectiva sobre a prática social da escrita. Campinas: Mercado das Letras, 1995.

MARINHO, M. Letramento: a criação de um neologismo e a construção de um conceito. In: MARINHO, M; CARVALHO, G. T. (Orgs.). Cultura escrita e letramento. Belo Horizonte: Editora UFMG, 2010.

MONTEIRO, Castellano Fernandes Monteiro-Ioc-Fiocruz. Celular na Sala de aula como alternativa Pedagógica no cotidiano das escolas. Anais da 29a reunião anual daANPEd-Educação, cultura e conhecimento na contemporaneidade: Desafios e Compromissos. Caxambu: ANPEd, v. 29, 2006.

SCRIBNER, S.; COLE, M. The psychology of literacy. Cambridge: Harvard University, 1981.

SOARES, M. Práticas de letramento e implicações para a pesquisa e políticas de alfabetização e letramento. In: MARINHO, M; CARVALHO, G. T. (Orgs.). Cultura escrita e letramento. Belo Horizonte: Editora UFMG, 2010. p. 54-67

STREET, B. V. Literacy in Theory and Practice. Cambridge: CUP, 1984.

STREET, B. "What's "new" in New Literacy Studies? Critical approaches to literacy in theory and practice"., Current Issues in Comparative Education, 5 (2), p. 77-91, 2003.

STREET, B. V. Os novos estudos sobre o letramento: histórico e perspectivas. In: MARINHO, M.; CARVALHO, G. T. (Orgs.). Cultura escrita e letramento. Belo Horizonte: Editora UFMG, 2010. p. 33-53.

STREET, B. V. Letramentos sociais: abordagens críticas do letramento no desenvolvimento da etnografia e na educação. São Paulo: Parábola editorial, 2014

UNESCO. La lectura en la era móvil: Un estudio sobre la lectura móvil en los países en desarrollo. Organización de las Naciones Unidas para la Educación, la Ciencia y la Cultura, México, D. F., 2015. 